https://www.sworldjournal.com/index.php/swj/article/view/swj06-02-064 DOI: 10.30888/2663-5712.2020-06-02-064

\title{
УДК: 616.98:578.828ВІЛ-053.2:616.612-008.6-07
}

\section{DIAGNOSIS OF PROXIMAL TUBULOPATHY IN CHILDREN WITH HIV INFECTION ДИАГНОСТИКА ПРОКСИМАЛЬНОЙ ТУБУЛОПАТИИ У ДЕТЕЙ
С ВИЧ-ИНФЕКЦИЕЙ}

Allahverdieva Z.S. / Аллахвердиева 3.C. as.prof. / ac. проф. ORCID:0000-0002-5701-154X

Dnepropetrovsk Medical Academy of the Ministry of Health of Ukraine, Dnipro, st. Vernadskogo 9, 49044

Аннотация. Публикация посвящена диагностике проксимальной тубулопатии у детей с ВИЧ-инфекичией.

Ключевые слова: ВИЧ-инфекиия, дети, проксимальная тубулопатия, диагностика.

\section{Вступление}

У детей с ВИЧ-инфекцией наблюдаются поражение почек в том числе проксимальные тубулопатии [1]. Проксимальные тубулярные нарушения почек определяются как снижение способности проксимальных канальцев реабсорбировать небольшие молекулы, отфильтрованные клубочками, такие как глюкоза, фосфор и белки с низким молекулярным весом [2]. Причиной развития поражения проксимальных канальцев у детей является ВИЧинфекция, а также высокоактивная антиретровирусная терапия (ВААРТ) [3-4]. Незначительное количество публикаций, в основном зарубежных, свидетельствует о том, что диагностика проксимальных тубулярных канальцев у ВИЧ-инфицированных детей ограничена. Ряд исследований проводились в Африке, как регион с самой высокой глобальной распространенностью ВИЧинфекции [5]. В связи с этим актуально своевременная диагностика проксимальной тубулопатии у детей с ВИЧ-инфекцией.

\section{Основной текст}

Стандартными методами оценки проксимальной почечной тубулопатии, утвержденными Guidelines-European AIDS clinical Society, являются исследования в моче и крови фосфора, калия, глюкозы, мочевой кислоты, а также сывороточного бикарбоната. Определение уровня $\mathrm{pH}$, аминокислот, низкомолекулярных белков ( $\alpha 1$-микроглобулин, $\beta 2$-микроглобулин, ретинолсвязывающий белок), цистатина С в моче.

Венесуэльские авторы тубулярную дисфункцию у детей с ВИЧ-инфекцией ассоциировали с гиперкальциурией, оценив показатель кальциурии как соотношение кальция мочи к креатинину мочи [6]. Bwakura D., et al для оценки проксимальных тубулярных нарушений исследовали мочу на наличие глюкозы и белка качественным методом с помощью тест-полосок (Uricheck M10, Omnipharm). ВИЧ-инфицированным детям с положительным уровнем глюкозы в моче $(>+1)$ глюкометром анализировали капиллярную кровь (Glucoplus TM). Количественная протеинурия оценивалась при разовой моче как соотношение белка мочи к креатинину мочи. Нормальный диапазон данного показателя в моче - $<0,2$ г, промежуточного уровня- 0,2-3,0 
нефротического диапазона -> 3,5 г [ 7].

По данным великобританской литературы был проведен ретроспективный анализ у взрослых с ВИЧ-инфекцией. Исследовали одновременно уровень альбумина и белка в моче как соотношение альбумина мочи к белку мочи, а также соотношение альбумина мочи к креатинину. Данное измерение поможет отличить тубулярную протеинурию от гломерулярной. Соотношении альбумина мочи к белку мочи (AМ/БМ) $\leq 0,4$ указывает на ренальную тубулопатию [8]. Проведенный анализ ряд литературных источников свидетельствует о том, что данная диагностика оценки функции проксимальных канальцев у детей с ВИЧ-инфекцией не использовалась.

Установленными маркерами проксимальной тубулярной дисфункции у ВИЧ-инфицированных детей являются гипофосфатемия, нормогликемическая глюкозурия и повышенная фракционная экскреция фосфатов. Рассчитывается как соотношение фосфора мочи к фосфору сыворотки и соотношение креатинина мочи к креатинину сыворотки. Патология имеет место при >0,2 ммоль/л. Кроме стандартной методики, существуют другие методы исследования, которые помогут установить структурные тубулярные изменения. К ним относят определение таких биомаркеров в моче, как липокалин, ассоциированный с желатиназой нейтрофилов (NGAL) или эпидермальный фактор роста (EGF).

NGAL - белок с молекулярной массой 25 кДа, образующийся во всех клетках организма. Синтез его возрастает при попадании клеток в «стрессовые» условия. Из плазмы крови NGAL свободно фильтруется в клубочках почек. Затем в значительной степени реабсорбируется клетками проксимальных канальцев путем эндоцитоза и расщепляется. В связи с этим экскреция с мочой данного белка может иметь место только при проксимальной тубулопатии. К биомаркерам нефротоксичности, вызванным ВААРТ, относят N-ацетил- $\beta$-Dглюкозаминидаза, $\gamma$-глутамилтранспептидаза [9].

\section{Заключение и выводы}

Наиболее распространенным поражением почек у ВИЧ-инфицированных детей является проксимальная тубулярная дисфункция, основной причиной развития которой является антиретровирусные препараты (тенофовир, ламивудин, абакавир).

Заподозрить проксимальную канальцевую дисфункцию следует при наличии соотношения альбумина мочи к белку мочи (AМ/БМ) $\leq 0,4$, которая нуждается в расширении обследования - изучение фракционной экскреции фосфора, мочевой кислоты, калия, глюкозы, сывороточного бикарбоната, аминоацидурии, цистатина С и низкомолекулярных белков ( $\alpha 1-$ микроглобулин, $\beta 2$-микроглобулин, ретинол-связывающий белок) в моче.

Исследование уровня кальциурии у детей с ВИЧ-инфекцией также необходимо учитывать при диагностике проксимальной тубулопатии.

Стандартные методы диагностики, которые утверждены GuidelinesEuropean AIDS clinical Society, а также определение уровня NGAL в моче или EGF помогут выявить на ранней стадии проксимальные тубулярные нарушения у ВИЧ-инфицированных детей. 


\section{Литература:}

1. Mignon I., McCulloch et al. Kidney Disease in HIV-positive Children Semin Nephrol., 2008 Nov; 28(6): 585-594, doi: 10.1016/j.semnephrol.2008.09.001

2. Jia L. Zhuo, Xiao C. Proximal Nephron. Compr. Physiol., 2013 Jul 1; 3(3): 1079-1123. doi: 10.1002/cphy.c110061.

3. Priyanka Singh et al. Journal Nephrol. DEC-205-mediated internalization of HIV-1 results in the establishment of silent infection in renal tubular cells, 2007 Mar;18(3):780-7.doi: 10.1681/ASN.2006121307.

4. J. Wyatt C.M. et al. Antiretroviral medications: adverseeffects on the kidney. Adv. Chronic Kidney Dis.2010;17:72-82.

5. Kopp JB, Nelson GW, Sampath K, et al. APOL1 genetic variants in focal segmental glomerulosclerosis and HIV-associated nephropathy. J Am Soc Nephrol. 2011;22:2129-2137. doi: 10.1681/ASN.2011040388.

6. Corina Gonzalez, G. Ariceta et al. Hypercalciuria is the main renal abnormality finding in Human Immunodeficiency Virus-infected children in Venezuela, European Journal of Pediatrics volume 167, pages509-515(2008).

7. Mutsawashe F., Bwakura-Dangarembizi et al. Proximal renal tubular function in HIV-infected children on tenofovir disoproxil fumarate for treatment of HIV infection at two tertiary hospitals in Harare, Zimbabwe, 2020; 15(7). doi: 10.1371/journal.pone.0235759

8. Samarawickrama A., et al. Simultaneous measurement of urinary albumin and total protein may facilitate decision-making in HIV-infected patients with proteinuria First published: 14 March 2012 https://doi.org/10.1111/j.1468-1293.2012.01003.x

9. Sofia Perazzo, Ángel A., et al. Urinary Biomarkers of Kidney Diseases in HIV-infected children, 2015 Jun; 9(0): 490-500. doi:10.1002/prca.201400193.

Abstract. The publication is devoted to the methods of investigation of proximal tubulopathy in HIV-infected children.

Key words: HIV-infection, children, proximal tubulopathy, diagnostics. 